\title{
O FAZ-DE-CONTA EM CRIANÇAS COM DEFICIÊNCIA VISUAL: IDENTIFICANDO HABILIDADES ${ }^{1}$
}

PRETEND PLAY IN VISUALLY IMPAIRED CHILDREN: IDENTIFICATION OF BILITIES

\author{
Luciana HUEARA ${ }^{2}$ \\ Carolina Molina Lucenti de SOUZA ${ }^{3}$ \\ Cecília Guarnieri BATISTA ${ }^{4}$ \\ Mariana Belloni MELGAÇO ${ }^{5}$ \\ Flávia da Silva TAVARES6
}

\begin{abstract}
RESUMO: o presente trabalho tem por objetivo descrever modos de brincar de crianças com deficiência visual na situação de brincadeira faz-de-conta em pequenos grupos, enfocando a construção de conhecimentos. Participaram do projeto quatro crianças de quatro a sete anos, com diagnóstico de deficiência visual (baixa visão ou cegueira), algumas com outros problemas orgânicos associados. A maioria freqüentava pré-escola; e várias crianças eram caracterizadas por alterações no desenvolvimento e/ ou apresentavam dificuldades escolares. Foram realizadas seis sessões com dois grupos de crianças, que duravam em média 25 minutos, nas quais eram oferecidos diferentes brinquedos propícios ao faz-de-conta (miniaturas de cozinha e quarto, bonecos e carrinhos). As sessões foram filmadas, transcritas e analisadas, buscando-se selecionar trechos representativos de capacidades das crianças, em suas várias manifestações. A análise das transcrições permitiu a identificação de capacidades das crianças, relativas a: a) reconhecimento de objetos e criação de cenas; b) criação de narrativas e faz-de-conta; c) exploração de objetos por criança que usualmente recusava qualquer tipo de contato; d) construção conjunta de significados. Considerou-se que as situações de brincadeira faz-de-conta proporcionaram o reconhecimento de habilidades que normalmente não seriam notadas em atividades cotidianas e/ou dirigidas. A interação entre parceiros e a situação de brincadeira relativamente livre, mediada por adultos, que buscavam principalmente facilitar e propiciar o brincar, proporcionou um ambiente favorável às múltiplas elaborações das crianças. Essa proposta, com foco no processo de construção de conhecimentos e habilidades permitiu descrever e promover o desenvolvimento das crianças com deficiência, mais do que caracterizá-las por suas incapacidades.
\end{abstract}

PALAVRAS-CHAVE: deficiências da visão; desenvolvimento da criança; educação especial; brinquedos.

ABSTRACT: the aim of the present study was to describe some modalities of pretend play in visually impaired children during interactions in small groups. The project was developed with four children, aged 4-7 years, with a diagnosis of visual impairment (low vision or blindness), some of them with additional organic problems. Most of them were enrolled in preschool; some of them presented developmental alterations and/or school difficulties. The study comprised six sessions (about 25 minutes each session) with two groups of children. The available toys were typical of pretend play activities (miniature kitchen and bedroom pieces, cars and dolls, etc). The sessions were taped, transcribed and analyzed. Episodes which were representative of children's abilities were selected. Analysis allowed for the identification of children's capacities such as: a) recognition of objects and construction of scenes; b) creation of narratives and episodes of pretend play; c) exploration of objects by a child who usually refused any kind of contact; d) joint construction of meanings. Pretend play situations allowed the recognition of abilities which would normally remain unnoticed in daily or guided activities. Peer interaction and a relatively free play situation, mediated by adults, promoted an environment that was favorable to multiple kinds of elaboration by the children. This proposal, which focused on the process of construction of knowledge and abilities, rather than characterizing the children as to their impairments, enabled the description and enhanced their development.

KEYWORDS: visual impairments; child development; special education; play.

\footnotetext{
${ }_{1}^{1}$ Trabalho parcialmente financiado pelo FAEPEX (processos 0131/2000 e 1534/2003)

${ }^{2}$ Fonoaudióloga pela Universidade Estadual de Campinas - luciana.hueara@uol.com.br

${ }^{3}$ Fonoaudióloga pela Universidade Estadual de Campinas - carolmls_fono@yahoo.com.br

${ }^{4}$ Psicóloga pela PUC-Campinas, Mestre e Doutora pelo Instituto de Psicologia da Universidade de São Paulo; Docente do Cepre, Faculdade de Ciências Médicas da Universidade Estadual de Campinas cecigb@fcm.unicamp.br

${ }^{5}$ Fonoaudióloga pela Universidade Estadual de Campinas - melbelloni@yahoo.com.br

${ }^{6}$ Fonoaudióloga pela Universidade Estadual de Campinas - flaviast@fcm.unicamp.br
} 


\title{
1 INTRODUÇÃo
}

O brincar é um tema muito abordado no estudo do desenvolvimento humano. Dentre suas modalidades, a brincadeira do tipo faz-de-conta caracterizase por evidenciar o início do uso de diferentes formas de representação pela criança. A identificação do início da representação é particularmente importante no caso de crianças com deficiência, por ser um indicador de seu desenvolvimento.

Diferentes autores consideram que o brincar é um importante fator no desenvolvimento infantil, contribuindo na constituição social, motora, afetiva e cognitiva da criança. Lembram que por meio da brincadeira a criança recria situações e aprende a solucionar problemas, desenvolve a capacidade imaginativa, adquire comportamento voluntário, desenvolve habilidades físicas, supre necessidades e apropria-se do mundo que a cerca. Para Froebel (apud KISHIMOTO, 2002), o brincar privilegia a liberdade de escolha e ação da criança, "dá alegria, liberdade, contentamento, descanso externo e interno, paz com o mundo..." (FROEBEL, 1912, p.55, apud KISHIMOTO, 2002)

Vygotsky (1989) destaca a brincadeira faz-de-conta como uma situação que privilegia a promoção do desenvolvimento e o surgimento de novas formas de interpretação e entendimento do mundo real. Ele considera que o faz-de-conta cria uma zona de desenvolvimento proximal, ao referir-se às potencialidades das crianças, que podem emergir e se desenvolver numa situação de imaginação.

A complexidade envolvida na atividade lúdica pode ser notada por meio do olhar histórico de Huizinga (1971), ao discutir diversas características do brincar como fenômeno cultural e como característica definidora do ser humano. Para o autor, o jogo é carregado de significado; assim, as explicações que procuram lhe atribuir finalidades exclusivamente biológicas ou materiais são insuficientes. $\mathrm{O}$ autor admite não ser possível encontrar uma definição exata, lógica, biológica ou estética para o jogo. Portanto, devemos nos contentar em descrever algumas de suas características:

\begin{abstract}
Numa tentativa de resumir as características formais do jogo, poderíamos considerá-lo uma atividade livre, conscientemente tomada como 'não séria' e exterior à vida habitual, mas ao mesmo tempo capaz de absorver o jogador de maneira intensa e total. É uma atividade desligada de todo e qualquer interesse material, com a qual não se pode obter qualquer lucro, praticada dentro de limites espaciais e temporais próprios, segundo uma certa ordem e certas regras. Promove a formação de grupos sociais, com a tendência a rodearemse de segredo e a sublimarem sua diferença em relação ao resto do mundo por meio de disfarces ou outros meios semelhantes. (HUIZINGA, 1971, p. 16)
\end{abstract}

Embora não apresente uma definição fechada, o autor destaca importantes características do jogo, incluindo seu caráter livre, não sério e não lucrativo. Pela importância que dá a essa atividade para o ser humano, chega a rebatizar o Homo sapiens de Homo ludens. Nesse sentido, é com cautela que se deve abordar a questão do uso "pedagógico" dos brinquedos, e do qualificativo "lúdico", usado de forma indiscriminada para designar diferentes atividades educativas. 
Ao abordar a concepção de Fröebel sobre o jogo infantil, Kishimoto (2002) lembra que ele foi um dos principais defensores do caráter livre do brincar infantil, como um meio para garantir a espontaneidade da criança, considerada fundamental para seu desenvolvimento moral, intelectual e físico. Para ele, por meio da conduta lúdica livre, a criança espontaneamente expressava suas necessidades e impulsos interiores. Kishimoto lembra que Fröebel foi o criador do kindergarten (jardim de infância), e que propunha atividades lúdicas como parte do currículo. Fröebel defendia o "aprender brincando", e criticava características autoritárias e diretivas presentes no sistema educacional vigente em sua época, que, segundo ele, tolhiam a liberdade da criança e inibiam seu desenvolvimento integral. Sua teoria pedagógica defendia o equilíbrio entre diretividade e liberdade, entre respeito ao individuo e à coletividade.

Destacam-se, assim, algumas características do jogo: seu caráter espontâneo, sua possível utilização em sistemas educativos, embora com risco de perda de seu caráter central e seu potencial na promoção do desenvolvimento infantil. Essas características são importantes quando se aborda a questão do desenvolvimento de crianças com deficiência.

No início do século $X X$, a definição de deficiência apontava para origens biológicas, o que sugeria estabilidade dos quadros diagnosticados e poucas possibilidades de mudança. Essa concepção sofreu modificações no decorrer do tempo: a deficiência deixou de ser vista como um fenômeno pouco sujeito a alterações, como categoria relacionada a perfis clínicos estáveis. A ênfase passou para os fatores ambientais, incluindo os processos de aprendizagem que podem favorecer o desenvolvimento de pessoas com deficiência (MARCHESI; MARTÍN, 1995)

Na mesma direção, já no início do século XX, Vygotsky (1997) criticava concepções organicistas de deficiência, que davam ênfase à irreversibilidade das disfunções e levavam a prognósticos desfavoráveis quanto ao desenvolvimento dos considerados deficientes. Em seus estudos sobre crianças com deficiência, o autor concluiu que as funções relacionadas ao desenvolvimento da criança com deficiência mental eram as mesmas da criança com desenvolvimento típico: assim, as mesmas concepções teóricas e abordagens metodológicas poderiam ser utilizadas para o estudo desses processos, em todas as crianças.

Segundo Kassar (1995), muitas imagens atribuídas a crianças com deficiência estão associadas a algumas concepções que se tem de deficiência mental e a certas crenças e idéias cristalizadas pela sociedade. Essas imagens, tais como lentidão, falta de memória, apatia, ganham força, perpetuam-se e dirigem a maneira pela qual os adultos interagem com crianças com deficiência. A partir dessas idéias, impregnadas por estigmas que acabam por diminuir os portadores de deficiência, cria-se uma concepção de deficiente como um sujeito que possui uma capacidade de aprendizagem limitada e pré-definida. Essas crenças, no âmbito do brincar, levam a baixas expectativas quanto às possibilidades do brincar nessas crianças. 
Silva (2003), em revisão sobre o brincar de crianças com deficiência, dá ênfase a vários autores que enfatizam o brincar como recurso para favorecer o desenvolvimento dessas crianças. Sintetizando a contribuição desses autores, Silva afirma que, para eles, a atividade lúdica é importante para crianças com deficiência pois estas, freqüentemente, vivenciam situações de fracasso no desempenho de diferentes tarefas. Por outro lado, quando se encontram numa situação de brincadeira, as mesmas crianças ousam tentar novas alternativas e tendem a tomar iniciativas sem preocupação de atingir ou não um resultado. A partir da revisão realizada, Silva (2003) considera que todas as crianças brincam, não importa quão severa seja sua deficiência, mas que essa atividade evolui mais lentamente que em crianças normais, ainda que seguindo as mesmas etapas de desenvolvimento.

Em um estudo recente, Silveira, Loguércio e Sperb (2000) relatam um estudo de observação do brincar de crianças com deficiência visual, a fim de estudar como se estabelece a brincadeira simbólica dessas crianças em dois momentos diferentes: brincadeira espontânea e incentivo à brincadeira. Observaram crianças de 6 a 11 anos que freqüentavam pré-escola, utilizando brinquedos disponíveis na escola, e classificaram as brincadeiras de acordo com a classificação piagetiana das etapas de desenvolvimento do jogo: jogos de exercício, jogo simbólico e jogo de regras (PIAGET, 1978). Os resultados mostraram que a maioria das crianças, no contexto espontâneo, apresentam equilíbrio entre brincadeiras características do período sensório-motor (com exploração e manipulação dos objetos) e brincadeiras do período simbólico. Já na situação de brincadeira dirigida, observaram o predomínio de brincadeiras típicas do período simbólico.

A conclusão do estudo é de que, sob estimulação, as crianças podem alcançar um nível de desenvolvimento cognitivo bem mais elaborado. Para os autores, as crianças são capazes de se engajar em brincadeiras simbólicas, mas, no caso de crianças com deficiência visual, esse tipo de brincadeira é mais freqüente quando é dado um incentivo para essa atividade. Chamam a atenção para o papel da linguagem no desenvolvimento cognitivo dos cegos, durante as brincadeiras simbólicas: consideram que a estruturação do brincar foi sustentada pela linguagem oral, em diálogos envolvendo falas e solicitações das crianças, e também comentários e incentivos dos adultos.

Silveira, Loguércio e Sperb (2000) afirmam que as crianças com deficiência visual precisam "ser ensinadas a brincar", considerando que, quando comparadas a crianças videntes, brincam muito pouco ou, quando brincam, não elaboram nenhum tipo de jogo simbólico. Entretanto, há que considerar que as crianças do estudo têm idades superiores à idade típica em que se observa o jogo simbólico; assim, é possível que esse tipo de brincadeira seja visto como "infantil" por elas. Da mesma forma, o manuseio e exploração por crianças cegas mais velhas talvez não tenham as mesmas características do jogo de exercício, tal como descrito por Piaget para o período sensório-motor (1978), pelo fato de ser uma atividade mediada pela linguagem. Parece-nos que o central, no caso da criança cega, é a 
falta de oportunidades para contato com diferentes objetos e situações lúdicas. Talvez, mais importante que ensinar as crianças cegas a brincar, seria oferecer condições propícias para que aconteça a brincadeira, condições essas que favoreçam as iniciativas da criança.

Tendo em vista a importância do brincar, e visando o incentivo a essa atividade por crianças com deficiência, foi proposto o presente estudo. Seu objetivo foi descrever modos de brincar, por parte de crianças com deficiência visual, algumas com outras alterações de origem orgânica, para identificação de capacidades. Foram observadas situações de "brinquedo livre", ou seja, pouco dirigido por adultos, em pequenos grupos de crianças na faixa de quatro a sete anos, sendo oferecidos brinquedos e objetos para propiciar brincadeiras faz-deconta.

\section{Método}

\section{Participantes}

Participaram do projeto oito crianças, todas com diagnóstico de deficiência visual (cegueira ou baixa visão), algumas delas com problemas orgânicos adicionais. Eram integrantes de um grupo de convivência, como parte das atividades do Programa Infantil DV de um centro universitário.

As crianças constituíam dois grupos, com, respectivamente, cinco e três participantes. Serão apresentados os resultados relativos a quatro crianças, que permaneceram nas atividades do ano, com poucas ausências, caracterizadas a seguir:

\section{Grupo I: ${ }^{7}$}

Júlia, 5 anos e 1 mês, ${ }^{8}$ cegueira, microftalmia bilateral congênita, atraso no desenvolvimento neuropsicomotor. Tinha iniciado os atendimentos há aproximadamente seis meses e, no início, rejeitava objetos e aproximação de pessoas, e apresentava alguns movimentos repetitivos. No período da realização do projeto, iniciava contato esporádico com alguns objetos. Falava pouco, pronunciando palavras ou frases curtas (ex: “Deixa ela!"), sem manter diálogos. Não freqüentava programas educacionais, regulares ou especiais, fora dos grupos descritos, devido à não aceitação das instituições especializadas.

Gisela, 7 anos, diagnóstico de baixa visão por toxoplasmose ocular e calcificações cerebrais devido a infecção congênita. Freqüentava pré-escola regular, com queixas de curta permanência nas atividades propostas. A família tinha sido aconselhada a colocá-la em instituição especializada, e a proposta do Programa Infantil DV era de mantê-la na escola regular, com orientações periódicas à professora.

\footnotetext{
${ }^{7}$ Os nomes das crianças são fictícios. Os pais assinaram um Termo de Consentimento para autorização da participação das crianças no projeto.

${ }^{8}$ As idades se referem ao início da coleta de dados.
} 


\section{Grupo II:}

Inácio, com 7 anos e 3 meses, baixa visão moderada para perto, profunda para longe, corioretinite macular bilateral por toxoplasmose. Freqüentava pré-escola regular, com queixa de pouca atenção às atividades propostas pela professora. Nos grupos, era difícil obter sua colaboração, o que dificultava identificar suas capacidades.

Beatriz, com 7 anos e 2 meses, diagnóstico de cegueira por retinoblastoma com 5 meses no olho esquerdo e com 3 anos no direito. Freqüentava pré-escola particular, sem apresentar problemas de aprendizagem. Sua família tinha mais recursos financeiros que as demais famílias do projeto, o que lhe possibilitava maior diversidade de experiências.

\section{CONTEXTO DE OBSERVAÇÃo}

Os grupos de convivência dos quais as crianças participavam tinham como meta propiciar oportunidades de desenvolvimento nas áreas sócio-afetiva, cognitivo-lingüística e psicomotora. Buscava-se, dessa forma, oferecer condições que pudessem favorecer o processo de inserção dessas crianças em escolas regulares, ou, dependendo do caso, em outros tipos de recursos da comunidade.

As atividades realizadas pelos grupos incluíam contar e elaborar histórias, jogos envolvendo diferentes habilidades cognitivas, desenho e modelagem, e brincadeiras de vários tipos. As sessões, com duração de 90 minutos, eram semanais, com atividades em sala e em pátio, seguidas por período de lanche no refeitório. Algumas crianças recebiam outros atendimentos pela equipe multidisciplinar, e aos pais eram oferecidos diversos tipos de orientação.

\section{MAteriais}

Durante as sessões procurou-se disponibilizar brinquedos apropriados para a faixa etária das crianças do grupo, em quantidade suficiente para os participantes, e com características que favorecessem o faz de conta:

- móveis de cozinha de madeira e utensílios em miniatura, mantida a proporcionalidade entre os mesmos (geladeira, fogão, pia, mesa, cadeiras, pratos, panelas, xícaras, colher, botijão de gás);

- móveis de quarto com respectivos acessórios (camas de casal e solteiro, com colchão e estrado, baú, roupas de cama);

- bonecos articuláveis de madeira;

- carrinhos e caminhões de madeira e de plástico;

- blocos de madeira;

- piões. 
Além desses materiais, em algumas sessões também foram disponibilizados lápis e papel, massa de modelar, chocalhos e um boneco tipo Super-herói.

Para o registro, transcrição e análise das sessões foram utilizados câmera filmadora, gravador, televisão, vídeo cassete, fitas VHS e fitas cassete.

\section{Procedimento de coleta e análise de dados}

Foram realizadas seis sessões de brincadeira "livre", três por grupo, com duração média de 25 minutos, nas quais eram dispostos os brinquedos previamente selecionados pelo pesquisador. As gravações foram realizadas em uma sala com espaço suficiente para as crianças e os observadores, onde os brinquedos foram dispostos sobre um tapete.

As sessões foram filmadas, transcritas e analisadas. Para a análise, foram selecionados trechos representativos de capacidades das crianças, em suas várias manifestações.

Vários adultos estiveram presentes às sessões, e sua atuação envolveu: apresentação de comentários relativos às iniciativas das crianças, intervenção no caso de disputas, organização do espaço físico e, em alguns momentos, apresentação de propostas, objetos e explicações, de acordo com o interesse das crianças.

As sessões foram transcritas em seqüência temporal, com foco no grupo como um todo, ou, mais freqüentemente, nos subgrupos que estivessem desenvolvendo atividades conjuntas e distintas de outros subgrupos, enquanto estas durassem.

O material transcrito foi organizado em episódios, com base nas seqüências interativas de brincadeiras, habilidades e capacidades explicitadas. $\mathrm{O}$ conceito de episódio adotado foi o definido por Carvalho et al. (1996), que consideram como um episódio uma seqüência interativa ou trecho de registros em que seja possível delimitar um grupo de sujeitos pela organização espacial ou pela participação em determinada atividade.

\section{Resultados}

Os vídeos das sessões, bem como as transcrições, foram examinados várias vezes, buscando-se identificar exemplos de competências e capacidades das crianças, no que se refere à elaboração do faz-de-conta e, na ausência deste, de algum tipo de manuseio dos brinquedos. Foram selecionados e comentados episódios significativos, em relação a esses aspectos.

A análise das transcrições permitiu a identificação de várias capacidades nas diferentes crianças, relativas a: 1- reconhecimento de objetos e criação de cenas; 2- criação de narrativas e faz-de-conta; 3- exploração de objetos 
por criança que usualmente recusava qualquer tipo de contato; 4- construção conjunta de significados.

\subsection{ReCONHECIMENTO DE OBJETOS E CRIAÇÃo DE CENAS Episódio: TrabalHaNdo Na COZINHA}

Beatriz explora pela primeira vez miniaturas de madeira representando móveis de casa (quarto e cozinha). Esses objetos têm dimensões em torno de 20 cm em sua maior dimensão (comprimento), com portas que se abrem, e poucos detalhes além de puxadores e prateleiras (ex: o fogão não tem acendedores salientes). As camas têm estrado que se desloca e colchão.

Beatriz começa a pegar móveis de cozinha. Enquanto monta a cozinha, Beatriz retira objetos ora de um baú (móveis), ora de um saco com brinquedos (utensílios como panelas, pratos, etc), e os identifica.

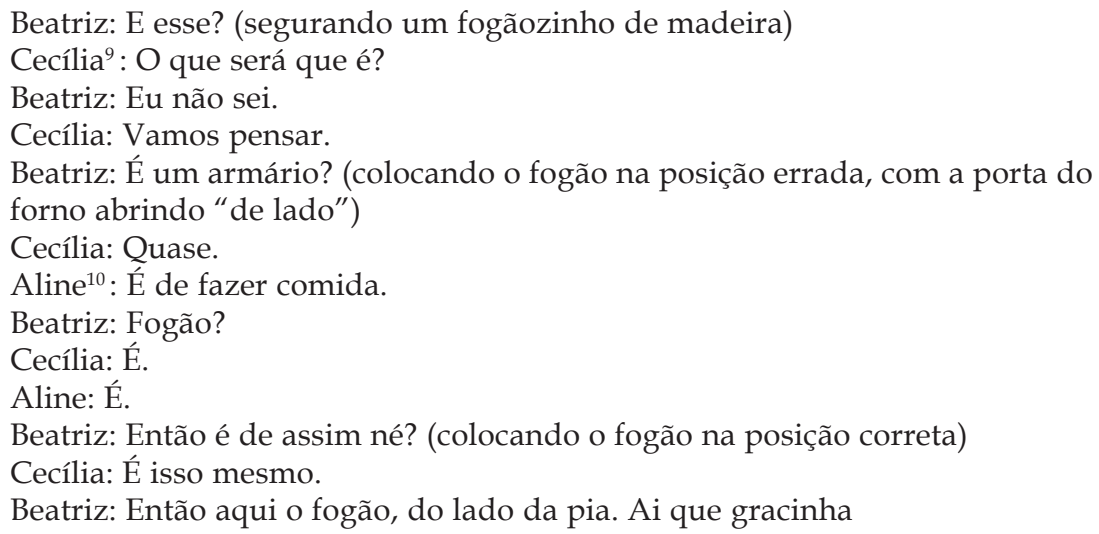

Em relação ao reconhecimento do fogão, Beatriz faz uma primeira hipótese, de que o objeto seja um armário, e o coloca na posição de um armário. Quando recebe a informação de que é "de fazer comida", ela pergunta se é um fogão (e não, por exemplo, uma panela, mantendo a coerência do diálogo, focado nos móveis de madeira, e não nos utensílios de cozinha). Imediatamente, coloca a peça na posição convencional de um fogão, com a porta basculante na posição da porta dos fogões convencionais.

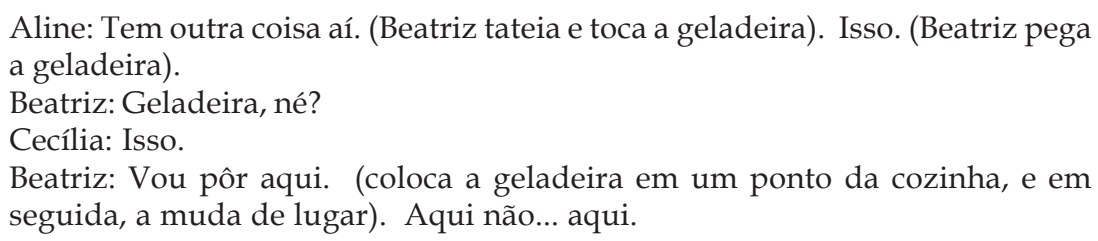

\footnotetext{
${ }^{9}$ Cecília - responsável pelos atendimentos

${ }^{10}$ Aline - psicóloga, participante do Programa de Aprimoramento: Psicologia do Desenvolvimento e Deficiência (Unicamp-Fundap).
} 
Aline indica que existe mais um móvel (geladeira), e Beatriz imediatamente o identifica como geladeira. Para entender a pronta identificação desse objeto por Beatriz, é relevante saber que, alguns minutos antes, ela tinha pegado a geladeira e perguntado se era um armário. A resposta tinha sido de que, nessa cozinha, só havia um armário, o que estava em baixo da pia. Depois dessa explicação, Beatriz tinha dito: "Então, esta é a geladeira", e a tinha colocado no chão. Agora, quando está completando a organização da cozinha, a dica de Aline "Tem outra coisa aí" é suficiente para que ela identifique o objeto remanescente como "geladeira".

Continuando a organização da cozinha, Beatriz pega o bujão de gás:

Beatriz: Olha o bujão de gás. O bujão de gás. Pertinho do fogão. (colocando-o junto ao fogão)

Observa-se que, em uma situação contextualizada, Beatriz é capaz, não somente de identificar, mas também de atribuir a função adequada aos objetos miniatura. O papel do adulto nessas situações restringiu-se a "dicas" que se enquadravam no contexto da brincadeira e que auxiliavam a criança no reconhecimento dos brinquedos sem, no entanto, fazê-lo por ela.

\section{EPISÓDIO: "Hora de ARRUMAR A CAMA"}

Ainda na brincadeira de casinha, Beatriz arrumava o quarto utilizando caminhas de madeira e pequenos retalhos de pano que seriam os lençóis.

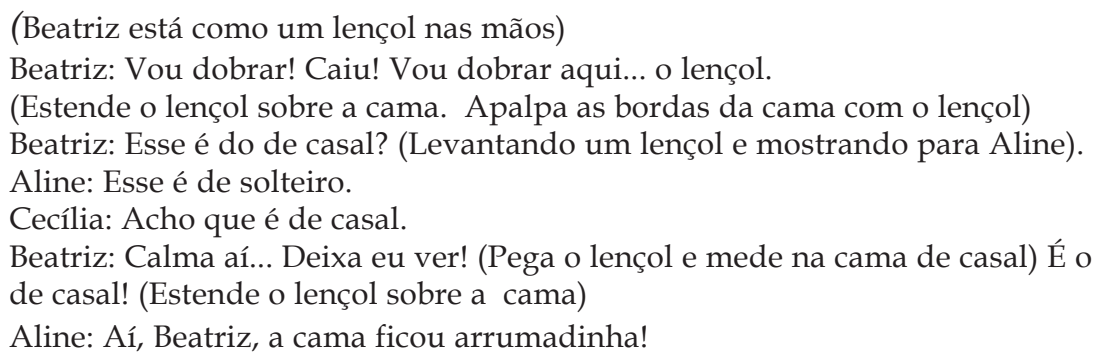

Nesse exemplo, os adultos presentes dão informações contraditórias (de fato, os lençóis não têm grande diferença de tamanho). Beatriz dá a solução, ao medir o lençol na cama.

Novamente é possível verificar a habilidade de Beatriz de reconhecer e lidar, com grande facilidade, com os objetos oferecidos mesmo que eles não ofereçam muitas pistas para sua identificação. Para isso ela resgata conhecimentos do uso cotidiano desses objetos e de papéis sociais. No episódio sobre arrumação da cama, foi capaz de dizer que o lençol era de casal, ao associar o tamanho do mesmo com o tamanho da cama. O desempenho de Beatriz nesse e nos demais episódios evidencia grande capacidade de elaboração conceitual e aquisição de conhecimentos. Mostra também, que o reconhecimento de objetos por crianças cegas não é uma tarefa meramente tátil, mas principalmente conceitual. 


\subsection{CriaÇão de Narrativas E FAZ-DE-CONTA EPISÓDIO: "COMIDA PARA O NENÊ"}

Gisela manipula um copinho com massinha, e faz de conta que é comida. Aline interage com Leôncio (criança que participou do grupo por poucas sessões), que está com um boneco.

Gisela: A nossa receita! (manipula o copinho com massinha)

Aline: (dirigindo-se a Leôncio) Põe o nenê na cadeira, põe.

Gisela: (dirigindo-se ao boneco de Leôncio) Tá com fominha, nenê? Tô fazendo comida prá ele! Tô fazendo comida prá ele! (fala para o boneco)

Gisela inicia uma brincadeira de faz-de-conta, por iniciativa própria. Em seguida, dirige-se à dupla em interação (Aline era um dos adultos com quem Gisela mais interagia) e incorpora sua brincadeira (fazer comida) à atividade entre Aline e Leôncio (manusear o boneco), oferecendo comida ao "bebê".

\section{EPISÓDIO: "ViaJANDO"}

Gisela manipula o baú de plástico grande que guarda os brinquedos. Ela o vira para baixo, batuca e depois senta-se sobre ele.

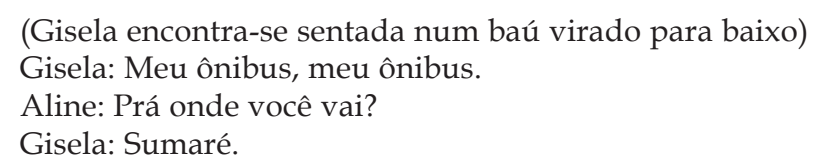

Em vários momentos, Gisela utilizou objetos disponíveis como substitutos de objetos reais, à medida que sustentavam uma ação lúdica como, por exemplo, na elaboração de um pequeno faz-de-conta no qual o baú tornou-se seu ônibus.

Este episódio ilustra também como a criança é capaz de trazer elementos da cultura para a atividade de brincadeira. "Sumaré" é a cidade em que a criança mora e, este dado é utilizado na elaboração do seu faz-de-conta.

\section{EpIsódio: “OlHa a cobra!"}

Inácio manipula um brinquedo de encaixe, com peças retas e curvas, cujas peças formam várias figuras, sendo a mais convencional uma cobra (o jogo de peças inclui uma cabeça). O brinquedo estava sobre um móvel, à parte dos brinquedos disponíveis nas caixas, e foi solicitado por Inácio.

\footnotetext{
Inácio: Aí a cobra saiu... SI. Aí quando o homem saiu... SI. Aí quando o homem saiu, quando o homem saiu, aí a cobra saiu aí... pega essa cobra aqui. Aline: Meu Deus! A cobra escapou! Inácio: Pega essa cobra, aqui atrás. Ióo... Ióo... (imitando uma sirene). Mm... mm... (imitando um motor). A cobra!!!

Aline: Aqui a cobra.

Inácio: Aah. Sua cobra! Você escapou... Cuidado, Cecília...
} 
Cecília: De novo escapou essa cobra... que perigo! Ai, meu Deus!

Inácio: É verdade... a cobra é forte. ... bii... bii.

Neste exemplo Inácio mostra uma certa independência em relação aos adultos para elaborar suas brincadeiras, que passam a ser gradualmente mais complexas. Este episódio traz exemplos de alguns recursos como gestos, vocalizações e posturas utilizadas pelas crianças, para representação de papéis, atribuição de significados a objetos e criação de um ambiente de faz-de-conta e de fantasia. Trata-se de atitudes que evidenciam capacidades de representação por parte das crianças.

\section{EPISÓDIO: “SUPER 15"}

Desde o inicio desta sessão, Inácio se interessou especificamente pelo boneco "Super 15", com o qual permaneceu durante a maior parte da sessão. Nesse ano, tinha sido iniciada a campanha publicitária de uma companhia telefônica, a partir da figura do Super Homem, criando o Super 15, com características semelhantes às do Super Homem (capa, capacidade de voar em alta velocidade, etc). Entre os brinquedos disponíveis, estava um boneco do Super 15, de plástico, com capa de tecido. A seguir, apresenta-se o trecho de uma das narrativas criadas por ele com o boneco.

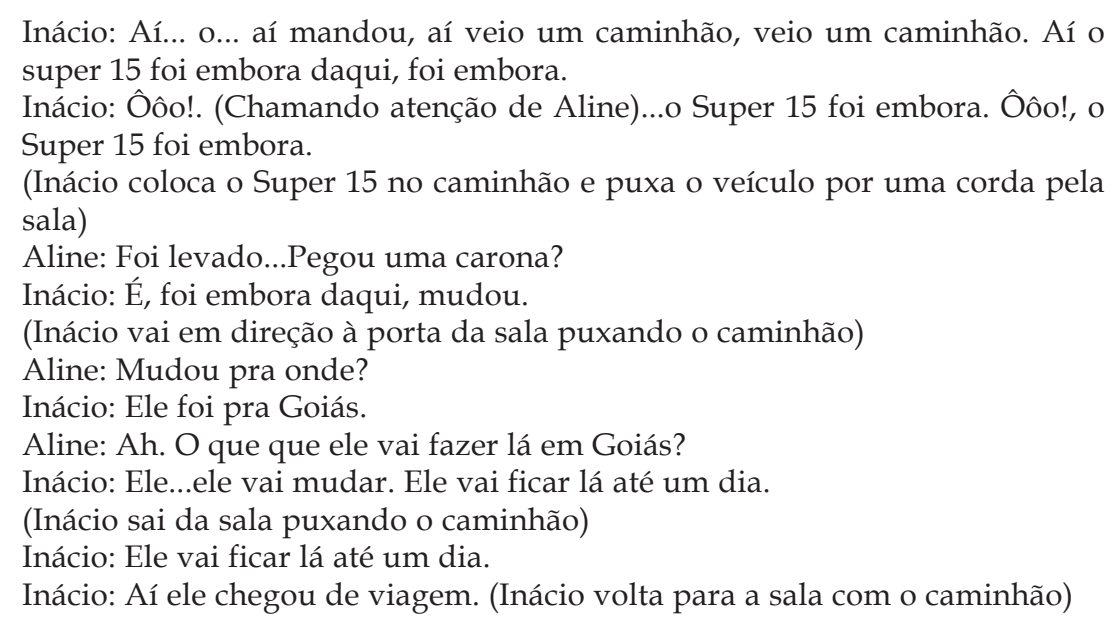

Inácio demonstrou habilidade na construção de narrativas elaboradas, muitas vezes relacionando o real e o imaginário. O episódio acima é parte de uma das diversas narrativas bastante complexas e ricas em detalhes que foram criadas por ele e envolviam o super-herói (Super 15).

Nesse trecho é interessante também, notar a relação entre o real e o lúdico, que aparece quando Inácio se vê na oportunidade de responder, ainda que no contexto lúdico, sobre algum destino de viagem (Aline: Mudou pra onde? / Inácio: Ele foi pra Goiás.) Sabe-se que Inácio possui parentes em Goiás, e recentemente havia viajado para lá (o que, provavelmente, também explica a ênfase na temática da cobra). 
Foi possível observar que situação lúdica propiciou o aparecimento de capacidades de elaboração e permanência na atividade, que raramente eram observadas em outras propostas mais semelhantes às tarefas escolares.

\title{
3.3 EXPLORAÇÃO DE OBJETOS POR CRIANÇA QUE USUALMENTE RECUSAVA QUALQUER TIPO DE CONTATO
}

A participação de Júlia no grupo era encorajada, mesmo quando ela não participava plenamente das atividades. No período em que o estudo foi realizado, tinham sido reduzidos os episódios de rejeição de pessoas e objetos, e ela começava uma exploração rudimentar de alguns objetos. Os exemplos apresentados referem-se, em vários casos, à síntese de vários episódios observados.

\section{EXPLORANDO A BOCA}

Em vários episódios, Júlia pegava objetos e os levava à boca. Lambia, chupava, e, aos poucos, passou a tateá-los, também de forma exploratória. O uso da exploração de objetos pela boca foi observado em um estudo longitudinal realizado por Preisler (1997) na Suécia, em crianças cegas em torno de dois anos. A autora observou que, por volta dos três anos, a exploração passou a ser feita predominantemente com as mãos. Como Júlia estava iniciando sua exploração de objetos, inicialmente, a exploração com a boca não foi desencorajada.

\section{Desviando de objetos}

\author{
(Júlia anda em direção a uma mesa, com risco de colidir). \\ Aline: "A mesa, Júlia!" \\ (Júlia muda de direção, desviando da mesa).
}

\section{RODANDO CARRINHO}

Por várias vezes, Júlia foi observada rodando um carrinho de madeira. Não era possível dizer se ela atribuía significado convencional a esse movimento. Entretanto, representava uma nova forma de uso do objeto, superior às anteriores.

\section{Ajeitando a SAia}

Júlia está sentada no chão, com as pernas abertas, rodando o carrinho no espaço entre as pernas. O carrinho bate em sua mini-saia. Ela muda a posição da saia, de modo a facilitar o deslocamento do carrinho.

\section{Cantarolando}

Ao explorar um brinquedo, Júlia começou a cantarolar a introdução da música "Vira-Vira" dos Mamonas Assassinas. A situação descontraída, de 
exploração de objetos sem excesso de orientações, provavelmente propiciou a evocação espontânea de canção aprendida em outro contexto, e que não tinha sido apresentada no grupo, anteriormente.

\section{DeiXando de colocar objetos NA Boca}

(Após vários pedidos para tirar os objetos da boca, Júlia continua com o caminhão na boca. Cecília tira o caminhão de sua boca.)

Cecília: Na boca não.

(Júlia tira o caminhão da boca)

(Júlia coloca novamente o caminhão na boca).

Aline: Sem pôr na boca, Júlia!

(Júlia joga o caminhão para trás, resmungando).

(Algum tempo depois, ela mesma tira o pião da boca e diz: "Não põe na boca".)

Nesse episódio, é observado o atendimento da solicitação de tirar o objeto da boca, por pouco tempo, e depois, novamente, sob protesto. Mais tarde, a própria Júlia dá o comando para tirar o objeto, e ela atende a esse comando.

Provavelmente, Júlia, por estar iniciando outras formas de contato com objetos, começa a poder prescindir da exploração com a boca, embora esta ainda seja uma forma bastante utilizada.

\subsection{ConstruÇão CONJUNTA DE SIGNIFICADOS EPISÓDIO: "A cama tÁ FURADa!"}

Gisela remexe no baú e retira os objetos de casinha. Pega a cama de casal e começa a montá-la sobre o tapete.

\footnotetext{
Gisela: Olha, quanta coisera!

Gisela: Ah! Eu quero a caminha ! (retira a caminha do baú, com os pés para cima; caem o estrado e o lençol)

Gisela: Ah, não! A cama tá furada. (estando a cama com os pés para cima, Gisela pega o estrado e tenta colocá-lo). Por que tirou isso aqui? Isso aqui é o quê? (referindo-se ao estrado da cama)

Aline: Não é assim que monta Gisela, é do outro lado da cama. Põe ela direito! (Gisela vira a cama, tenta encaixar o estrado e não consegue)

Aline: Não ! Não é assim o estrado ! Põe direitinho !

Gisela: Não sei por o estrado! (Aline ajuda a colocar o estrado, e Gisela coloca o colchão)
}

Na interação do adulto com a criança, ocorrida durante o episódio, Aline utiliza um termo novo (estrado), desconhecido por Gisela. No decorrer da atividade, Gisela utiliza o termo novo, dando indicações de tê-lo compreendido. Aline faz uma parte da tarefa de montar a cama (estrado) e Gisela completa o trabalho (colchão). 


\section{EPISÓDIO: “RodA, PIÃo!"}

Até o momento Beatriz havia brincado apenas com os objetos de casinha e algumas bonecas.

(Beatriz pega um pião com as duas mãos, e o explora com os dedos. É um pião de madeira, tendo, na parte superior, eixo para enrolar o barbante, e argola para segurá-lo enquanto se puxa o barbante. É mais fácil de rodar do que o pião de madeira convencional, e permanece girando por mais tempo, sem risco de tombar).

Beatriz: E o que que é isso?

Gustavo $^{11}$ : Pião.

Aline: É um pião.

Cecília: Quer ver como faz um pião, Beatriz ? (pegando o pião)

(Cecília demonstra a Beatriz como rodar o pião, colocando a mão de Beatriz junto à sua, para que ela possa acompanhar o preparo do pião para rodar, o que ocorre por duas vezes. Beatriz chega a tocar, de leve, no pião rodando. Em seguida, Beatriz vai brincar com as caminhas de brinquedo).

(Depois de algum tempo, retorna ao pião e solta-o corretamente, sozinha.)

Observa-se que a explicação sobre o funcionamento do pião foi apresentada, sem insistência para que Beatriz executasse o processo. Depois de algum tempo, ela retomou o pião e conseguiu rodá-lo de modo correto. Uma vez que o adulto não insistiu nessa execução, a iniciativa coube a ela, e eventuais dificuldades teriam menos conotação de fracasso do que se tivesse havido grande insistência.

Verifica-se que Beatriz conseguiu manusear o pião corretamente, sem a necessidade de uma instrução minuciosa sobre cada detalhe do pião, e seu modo de funcionamento, crença comum entre os professores de cegos. A retomada do pião, e um breve exame do mesmo, junto com a experiência anterior de tocar a mão do adulto enquanto este rodava o pião, foi suficiente para que ela apreendesse o processo.

\section{EPISÓDIO: “BLOCO PESADÃO"}

Gisela brinca com os blocos de madeira, manipulando-os e empilhandoos com o objetivo de fazer uma casa.

Gisela: Cadê, cadê o bloco?

Gisela: Ó gente! vou fazer minha casa. Gente, chama a Luana pra ver. (os blocos caem)

Gisela: Ah, não! Eu vou martelar. (martela um bloco usando outro bloco)

(Gisela começa a recolocar os blocos, cai mais uma peça)

Gisela: Ah, a casa caiu.

Gisela: Esse aqui é pesado, olha. (pega um cilindro azul e leva para a Cecília)

Aline: É pesado (confirmando).

Carolina $^{12}$ : É pesadão.

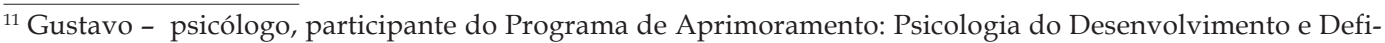
ciência (Unicamp-Fundap).

${ }^{12}$ Carolina - estagiária, aluna de Fonoaudiologia.
} 
Gisela permaneceu nessa atividade por grande parte da sessão, o que não era usual de sua parte - a permanência em uma atividade. Nesse episódio, ela mostrou habilidade de discriminar pesos e medidas de alguns objetos. (O bloco que Gisela levou para Cecília ver era, realmente, um dos mais pesados do conjunto).

\section{EPISÓDIO: "EscANDALOSA"}

Nesse momento Beatriz brinca de casinha e elabora um pequeno fazde-conta com uma boneca (semelhante à boneca Barbie).

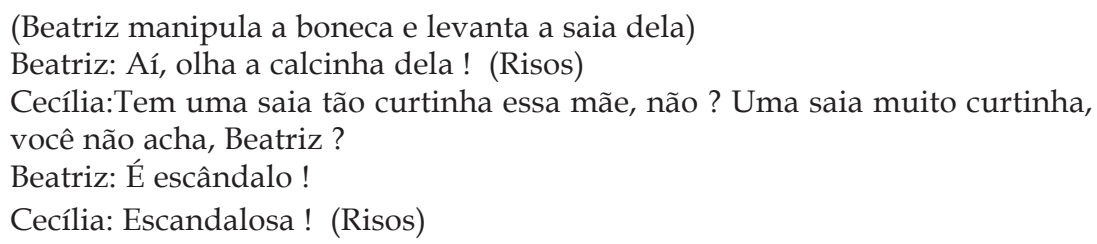

Nesse trecho percebe-se a apropriação de valores transmitidos e construídos culturalmente e a assimilação de situações da vida cotidiana em seu brincar. A relação estabelecida por Beatriz, entre usar uma saia curta e escândalo, mostra a influência que o contexto social exerce sobre a criação do faz-de-conta.

Em crianças dessa idade é comum o interesse em explorar aspectos da sexualidade como as roupas íntimas e as diferenças sexuais entre homens e mulheres. No trecho transcrito, Beatriz demonstra esse interesse, mesmo sem enxergar a boneca, apenas manipulando e verificando que a mesma usava calcinha.

\section{Discussão E CONCLUSÃo}

Os episódios selecionados permitiram evidenciar diferentes capacidades das crianças participantes. Os episódios de Beatriz (item 3.1) mostraram que o reconhecimento de objetos pela criança cega não depende apenas do tato. Beatriz tem conhecimento sobre rotinas e sobre características das cenas montadas, estabelece exploração organizada dos objetos, e mantém, o tempo todo, diálogo com adultos. A exploração tátil leva ao reconhecimento de atributos e propriedades dos objetos, confirmados pelos adultos. Com a segurança dessa confirmação, Beatriz prossegue na exploração desses objetos e na elaboração de cenas, numa interação em que estão em jogo percepção tátil, conhecimentos anteriores, e as ações de confirmação e fornecimento de pistas por parte dos adultos.

Essas evidências estão de acordo com as colocações de Vygotsky (1997), quando reconhece que a cegueira cria dificuldades para a participação em muitas atividades da vida social, mas, por outro lado, mantém a principal fonte de conteúdos de desenvolvimento: a linguagem. Ao fazer essas afirmações, o autor concordava com outros autores russos de sua época, para os quais a utilização da linguagem se constituía no principal meio de superar as conseqüências da cegueira. 
Quanto à criação de narrativas e brincadeiras faz-de-conta (item3.2) foi interessante verificar que as mesmas foram protagonizadas por crianças cujo diagnóstico levava a previsões de baixo desempenho, e cuja história escolar começava a confirmar essas previsões. Eram crianças que apresentavam baixo nível de atenção e, conseqüentemente, baixo rendimento em tarefas aparentemente bem planejadas, que visavam a introdução de conhecimentos escolares (ex: pareamento de figuras e letras, identificação de crachás, etc). Na situação de brincadeira, as histórias e cenas criadas evidenciaram o domínio e aplicação de muitos conhecimentos do cotidiano, bem como a presença de capacidades tais como atenção sustentada, raciocínio lógico e elaboração de narrativas coerentes. Os resultados sugerem, portanto, que a identificação do potencial de desenvolvimento dessas crianças não seja feita apenas com base no diagnóstico e na descrição de suas dificuldades presentes. Essa identificação deve ser embasada, também, em uma avaliação abrangente, que contemple a observação dessas crianças em diferentes situações de interação, com diferentes parceiros. Dessa forma, avaliação e promoção do desenvolvimento passam a ser vistas como interligadas, e centradas na busca de capacidades, mais que na caracterização de dificuldades, muitas já cristalizadas, conforme discutido por Batista; Nunes e Horino (2004).

Os episódios mencionados no item 3.3, relativos ao início da exploração de objetos por parte de Júlia, constituem exemplos de um processo de aquisição de novas habilidades que não é linear, e que aparenta ser muito lento. Entretanto, se comparados aos relatos do início dos atendimentos, mostram progressos, que sugerem aquisições. De fato, observações do desempenho de Júlia, posteriores às do presente projeto, indicam uma evolução em vários aspectos: exploração diversificada de objetos com as mãos, uso convencional de alguns objetos e brinquedos e compreensão de orientações simples. Uma descrição mais elaborada dessas mudanças é apresentada em Silva e Batista (no prelo).

Quanto aos episódios mencionados no item 3.4, relativos à construção conjunta de novos conhecimentos, são apresentados exemplos que mostram diferentes níveis de intervenção do adulto na atividade das crianças. Há situações em que são dadas instruções explícitas sobre desempenho (ex: pião), e outras em que o adulto dá dicas breves ou confirma o que a criança fala ou faz. De acordo com Cruz e Smolka (1995), a interação do adulto, por meio da palavra que aponta/ nomeia/recorta objetos e ações, articula relações e interações culturalmente determinadas, dá significado ao objeto e possibilita a apreensão do mesmo pela criança. Dessa forma, é evidenciado o papel do adulto como parceiro mais competente nas interações e na construção conjunta de conhecimentos.

Em síntese, considerou-se que, no presente trabalho, a análise dos episódios permitiu identificar a situação de brincar faz-de-conta como importante indicador do desenvolvimento infantil, no caso das crianças com deficiência. Durante a brincadeira, as crianças revelaram competências que normalmente não eram reconhecidas nas atividades cotidianas, e em diferentes modos de avaliação mais dirigida. 
Além disso, a situação de brincadeira relativamente livre, mediada por adultos, constituiu-se em ambiente favorável às múltiplas elaborações das crianças. As crianças evidenciaram grande capacidade de representar papéis, criar cenas, estabelecer regras, compreender o uso de objetos cotidianos, reconhecer e transmitir aspectos culturais, sendo reconhecidas, nesse contexto, mais por suas possibilidades que por suas incapacidades.

Desta forma, a descrição de modos de brincar, objetivo do trabalho, levou à constatação de múltiplos exemplos de capacidades das crianças, que eram menos evidentes em situações de ensino e avaliação estruturadas e padronizadas. Os resultados sugerem novos estudos voltados para a análise das modalidades de interação observadas na situação de brincadeira (entre adulto e criança, e entre parceiros), e sua contribuição para o desenvolvimento de crianças com deficiências.

\section{REFERÊNCIAS}

BATISTA, C. G.; NUNES, S. S.; HORINO, L. E. Avaliação assistida de habilidades cognitivas em crianças com deficiência visual e com dificuldades de aprendizagem. Psicologia: Reflexão e Crítica, Porto Alegre, v 17, n. 3, p. 381-393, 2004.

CARVALHO, A. M. A. et al. Registro em vídeo na pesquisa em psicologia: reflexões a partir de relatos de experiência. Psicologia: Teoria e Pesquisa, Brasília, v.12, p. 261-267, 1996.

CRUZ, M. N.; SMOLKA, A. L. B. Gestos, palavras, objetos: uma análise de possíveis configurações na dinâmica interativa. In: OLIVEIRA, Z. M. R. (Org.) A criança e seu desenvolvimento: perspectivas para se discutir a educação infantil. São Paulo: Cortez, 1995.

HUIZINGA, J. Homo ludens: o jogo como elemento da cultura. Trad. J. P. Monteiro. São Paulo: Perspectiva / EDUSP, 1971.

KASSAR, M.C.M. Ciência e senso comum no cotidiano das classes especiais. Campinas: Papirus, 1995.

KISHIMOTO, T. M. O brincar e suas teorias. São Paulo: Pioneira Thomson Learning editora, 2002.

MARCHESI, A.; MARTÍN, E. Da Terminologia do distúrbio às necessidades educacionais especiais. In: COLL, C.; PALACIOS, J.; MARCHESI, A. (Org.). Desenvolvimento psicológico e educação; necessidades educativas especiais e aprendizagem escolar. Trad. M. A. G. Domingues. Porto Alegre: Artmed, 1995, 3 v.

PIAGET, J. A formação do símbolo na criança. 3. ed. Trad. A. Cabral e C.M.Oiticica. Rio de Janeiro: Zahar, 1978.

PREISLER, G. Social and emotional development of blind children: a longitudinal study. In: Lewis, V. e Collis, G.M. (Org.) Blindness and psychological development in young children. Reino Unido: The British Psychological Society, 1997.

SILVA, C. C. B. O lugar do brinquedo e do jogo nas escolas especiais de educação infantil. 2003. 167f. Tese (Doutorado em Psicologia Escolar e do Desenvolvimento Humano) - Instituto de Psicologia, Universidade de São Paulo, São Paulo. 
SILVA, M. A.; BATISTA, C. G. Mediação semiótica: estudo de caso de uma criança cega, com alterações no desenvolvimento. Psicologia Reflexão e Crítica, no prelo.

SILVEIRA, A.; LOGUERCIO, L.; SPERB, T.. A brincadeira simbólica de crianças deficientes visuais pré-escolares. Revista Brasileira de Educação Especial, Marília, v. 6, p. 133-146, 2000.

VYGOTSKY, L.S.. A formação social da mente. 3. ed. Trad. J.Cipolla Neto, L.S.M. Barreto e S.C.Afeche. São Paulo: Martins Fontes, 1989.

VYGOTSKY, L. S. Obras escogidas, V-fundamentos de defectología Trad. J. G. Blank. Madri: Ed. Visor, 1997.

Recebido em 28/08/2006

Reformulado em 08/12/2006

Aprovado em 14/12/2006 